\title{
Host Community Attitude Toward Trade-off Between Tourism Development and Environmental Conservation: A Case Study of Palau
}

\author{
Po Yen Lee ${ }^{1}$, Lin $\mathrm{Qi}^{1} \&$ Peng $\mathrm{Li}^{2}$ \\ ${ }^{1}$ School of Hotel and Tourism Management, The Hong Kong Polytechnic University, China \\ ${ }^{2}$ Shenzhen Tourism College, Jinan University, China \\ Correspondence: Peng Li, Shenzhen Tourism College, Jinan University, China. E-mail: lipeng@sz.jnu.edu.cn
}

Received: Janaury 7, 2020

Accepted: February 11, 2020

Online Published: March 20, 2020

doi:10.5430/bmr.v9n1p21

URL: https://doi.org/10.5430/bmr.v9n1p21

\begin{abstract}
Palau is home to one of the purest marine ecosystems in the Pacific Ocean; however, since 2015, Palau has suffered an economic decline due to the negative environmental effects of over- tourism. The island country is at the crossroads of stagnation and recovery. The community attitude towards the trade-off between tourism development and environmental conservation are critical for forging a tourism strategy. This research attempts to identify the attitudes, values and beliefs of the community and proposes an appropriate plan within the current tourism scenario. The method of in-depth interviews and secondary data analysis were applied using NVivo software. The results showed that there are different viewpoints between the residents and the government, but there is one aspect that everyone agrees on: the need to develop tourism strategy that runs parallel to environmental conservation by upgrading Palau's tourism to provide a high-end product. This would ideally result in finding a balance between the needs of the host community and sustainable tourism in a win-win scenario.
\end{abstract}

Keywords: host community, sustainable tourism, Palau

\section{Introduction}

Tourism is one of the main economic drivers for many island countries. In the increasingly fierce competition of the global market, tourism resources are often consumed without restraint, resulting in the need for sustainable tourism to be put on the core agenda of tourism management and planning. The voice of the host community plays a significant role in the process of tourism planning (Homsud \& Promsaard, 2015). According to triple bottom line model (Wang \& Pfister, 2008), the impact of tourism on destinations involves environmental, social, cultural and economic aspects. Either positive or negative impacts would affect the community's attitudes towards tourism development. To research local residents' attitudes towards the tourism industry is significant for the development of sustainable tourism (Miyakunil el. al, 2018). Also, the community is one of the main stakeholders of tourism development; the residents should be encouraged to get involved in the decision-making and development process of tourism (Homsud \& Promsaard, 2015). Therefore, communicating with local stakeholders is a critical aspect of gaining support for sustainable tourism development.

As a tourist destination, Palau is dependent on its natural resources. Tourism is the main economic pillar in Palau: approximately 40\% of GDP in Palau resulted from the tourism industry in 2017 (IMF p4, 2019). The total population of Palau was 21,800 in 2017 and the ratio of local residents to visitors is 1:8 (PVA statistics, 2019). Consequently, the contribution of international tourists to the economy of Palau is becoming increasingly important. Nevertheless, Palau faces a dilemma regarding tourism development: over-tourism in previous years has had a serious, negative impact on the local ecological environment. Once the natural resources of this island are destroyed, the competitive advantage and livelihood of residents in Palau will be greatly impacted due to reduced tourism. Moreover, Palau is facing the threat of the decline of its main tourist market, which the national economic development relies on.

The tension between tourism development and ecological conservation is becoming increasingly obvious; the issue challenges policy makers to address concerns from different interests (Dredge, Jenkins, \& Whitford, 2011). In order to sustain the environment, it seems that Palau has to slow down its pace of tourism development. In recent years, Palau's policy documents began to emphasize the protection of natural and social-cultural resources (Stumpf \& Swanger, 2014). Tourism is also positioned as one of the driving forces to promote environmental management. In 
face of the perceived benefits and costs resulting from tourism, many disputes are aroused among stakeholders, such as trade-off between economic benefits and environmental conservation, conflicts between the residents and tourists in Palau, community disturbance caused by over-crowding by tourists. These development dilemmas have become controversial topics, mainly centering on the attitudes of local relevant stakeholders.

To solve the contradictions mentioned above, it is necessary to investigate the attitudes of local relevant stakeholders. The issues address the imbalance between local tourism economic revenue and ecologically sound environmental protection and require better sustainable tourism development strategies. However, most Pacific Asian countries failed to embrace the balance needed between economic development and environmental conservation (Delgado-Serrano, 2017). Also, there is limited research into Palau's dealings with the tourism industry. The lack of literature available has focused this current research on these questions: What are the host community's attitudes towards the impact of tourism development? What are the determinants of the host community's attitudes for tourism development?

To find the answers to these questions, this research aims to investigate the attitudes of the Palauan residents towards the various aspects and impacts of tourism development, the purpose of which being to bridge the gap in the available literature regarding the community's attitudes towards the tourism development of Palau. This research will be used to produce appropriate tourism planning with the purpose of developing Palau as a sustainable ecotourism destination, and will provide meaningful insights on how to manage the relationship regarding the tourism development between different stakeholders.

\section{Literature Review}

This research is aimed at investigating the attitudes of the Palauan residents towards the trade-off between tourism development and environmental conservation. The research theoretical framework is based on the following theories.

\subsection{Butler's Tourism Area Life Cycle (TALC, 1980)}

The theory of tourism area life cycle (TALC) is proposed by Richard Butler, a Canadian scholar in 1980. For decades, the TALC has guided researchers and governments when analyzing the development path of tourism destinations and predict future trends. TALC explicates that destinations (i.e. tourism areas) were like products, following certain patterns of development in the product life cycle. There are six stages of evolution destination cycle: exploration, involvement, development, consolidation, stagnation and decline or recovery stage. In the first stage, exploration, the tourists are mainly attracted by the natural or cultural assets of the destination. However, the tourism infrastructure is limited. In the second stage, involvement, the local tourism season begins to appear because of the increasing number of tourists. Then, mass tourism booms and tourism enters the third stage of development. Foreign companies enter the local tourism markets and invest in the purpose-built attractions. The destination thus relies heavily on tourism and enters the fourth stage, consolidation. When local residents feel that tourism is undermining their normal lives, tourism facilities decrease. In the final stage, the destination may stagnate, then, two trends may occur, decline or recovery. This final or turning stage may be used to interpret the current scenario of Palau.

The TALC model presumes that the capacity and resources of destinations are limited. Along with the increased numbers of tourists, the overall quality and temptation of the destination will decease gradually. The claim for the preservation and protection of tourism area will be aroused (Butler, 1980). However, some scholars question if "the tourism area" could be evolved from a small town to encompass a whole country; therefore, the capacity and resources should not be so easily limited from a country's perspective. Yet, Palau is a relative tiny island country with a population of only around 20,000 residents and hit its over-tourism limit in 2015. According to TALC, Palau as a destination faced potential risk factors at each stage (McKercher, 2005). In particular, Palau is facing the stagnation and decline stage at present time. It is therefore critical for Palau to reposition itself via enhancing its capacities and resources. Therefore, the TALC is assumed as an ideal framework to examine the tourism development in Palau.

\subsection{Social Exchange Theory (SET)}

Social exchange theory originated in the late 1950's. It advocates that social behavior can be analyzed from the perspective of the relationship between economic input and output. In a social interaction, people always tend to expand the benefits and reduce the costs. Social exchange theory is used by some scholars to explain the tourism phenomenon: the benefits or costs resulting from tourism activities will affect people's attitudes towards tourism development to a great extent. If they primarily benefit from the tourism industry, they will tend to have a positive attitude towards tourism development and support tourism. Conversely, when the benefits are less than their costs, 
they will hold a negative attitude and oppose tourism development (McCool \& Moisey, 2008; Nunkoo \& Ramkissoon, 2011).

Untong et al. (2010) identified that economic benefits have the most direct impact on the attitude of local residents towards tourism. This is because tourism brings direct economic income and more employment opportunities to local residents. Faulkner \& Tideswell (1997) pointed out that residents who depend on tourism for their livelihood have a positive attitude towards the contribution of tourism industry to the destination, and a tolerant attitude towards the negative impact. However, Schofield (2011) emphasized that when the destination entered the mature stage, community residents were more sensitive to the negative environmental impacts of tourism. The most noteworthy proposition of social exchange theory is proposed to achieve win-win through mutual exchange, which is the ultimate goal of all tourism destinations, including Palau.

\subsection{Resident-Tourist Emotional Solidarity}

Durkherm's theory of emotional solidarity is mostly used to assess the relationship between residents and tourists (Durkheim, 1912, 1995). The theory of emotional solidarity originated from sociology. Based on the theory of emotional solidarity, later researchers developed five dimensions to measure residents' attitudes towards tourism development, including welcoming nature, emotional closeness, sympathetic understanding (Woosnam \& Norman, 2010), contributions to the community and support for tourism (Wang \& Pfister, 2008). When residents show their welcoming nature to tourists, they recognize the contribution of the tourists to the development of the destination. They are proud to have visitors. When residents and tourists are emotionally close, they may develop friendships. When residents show sympathetic understanding to tourists, they may acknowledge similarities (Woosnam \& Norman, 2010).

The theory of emotional solidarity explores residents' attitudes towards tourism by measuring the relationship between residents and tourists, which takes into account the factors of emotional changes. The emotional bonds between tourists and residents in Palau vary over time. The dynamic factors need to be monitored and inferred to reach the solution plan of sustainability.

\section{Methodology}

\subsection{Research Concept}

To have a deeper view of community attitudes toward tourism development, this research is designed using the combined research concepts of primary and secondary research.

\subsubsection{Primary Research}

The thoughts and opinions of residents towards the development of tourism is a subjective perception, requiring the researchers to delve into the mindset of the interviewees in order to accurately understand their position. Originating from the naturalistic paradigm, qualitative research normally uses in-depth interview questions to guide the interviewees to describe their own experiences or feelings. Via this process, the interviewer can thus have empathy and be able to systemize the thoughts and behaviors of the interviewees (Lincoln \& Guba, 1985). Therefore, the in-depth interview is applied here to investigate the thoughts of the local residents in the first stage of this research.

\subsubsection{Secondary Research}

The secondary research has the strength of utilizing relevant existing data for research analysis. It is also an empirical exercise requiring a systematic method when collecting and evaluating vast amounts of primary data (Johnston, 2013). In this research, the method is assumed to access more data regarding the community attitudes toward tourism development.

\subsection{Data Collection}

The method of purposive sampling was used to select three different background residents. The interview questionnaire was semi-structured and divided into three parts: (1) demographics, including job, working experience and personal information, (2) the attitude and perception towards positive and negative impacts on the tourism development in Palau, and (3) the expectation for future tourism development in Palau (refer to Appendix II). Each interview took more than 30 minutes. With the permission of the interviewers, all interviews were electronically recorded and transcribed into word format. As well, some secondary materials were collected, including the Palau government's reports and three journal articles. 


\subsection{Research Procedure, Reliability and Validity Based on NVivo}

The research procedure included three stages using the analysis tool of NVivo: (1) organizing the interview materials and related literature, (2) converting the file format, importing it into NVivo and using the software to encode the data and arrange the nodes, and

(3) analyzing the conclusions. In the process of NVivo software, the collected data was divided into three groups: interview group, government literature, and research literature. In the word frequency analysis process, all word frequency analysis selects "synonyms" as the word frequency grouping criterion. This is because the grouping of "synonyms" can enhance the expression of word-centered ideas and improve reliability and validity.

The corresponding preparation for using NVivo software is specified as following: collect the data, convert web page data into a text format conforming to NVivo, convert text data without pictures to TXT, and convert pictures to DOC formats to ensure that picture information is not lost (if the data format is not converted, garbled characters will appear). Then run the software and create a new NVivo task (project). After running, search the word frequency in the software interface and export the corresponding word cloud. Word cloud is a form of information word frequency visualization. Objective data word clouds can show the objective development of the law of things. That is to say, in the "word cloud" figure, the larger the word size of a word, the more times this word (or synonyms) are mentioned. Correspondingly, the more concentrated this word (or synonyms) expressed in the interview. The word cloud of subjective interview material can clearly express the true feelings of the interviewees about things. The following content of this study will objectively analyze the word frequency according to different data sources, and analyze the emotional direction represented by the data. Because the target respondents of this study were in Palau, the research area was clearly tourism oriented. Therefore, in this study, when counting word frequency, "Palau" and "Tourism" were set as stop words to improve the reliability and effectiveness of word frequency statistics. The NVivo encoding and decoding process is explained in Appendix 1.

\subsection{Empirical Case Analysis for Tourism Development of Palau}

The Republic of Palau, located in the Western Pacific, is one of the pivotal portals for the Pacific to enter Southeast Asia. The land area is 459 square kilometers, and the marine exclusive economic zone (EEZ) is about 62.9 square kilometers. There are more than 500 volcanic and coral islands in Palau, of which only 12 have permanent residents. In 1989, Palau was named one of the seven underwater wonders in the world.

Palau is a developing island destination in the world, which is famous for its abundant marine resources, including coral reefs, a shark sanctuary, reef fish and a unique island culture. Ecotourism is an important motivation for tourists to Palau (Wabnitz, et. al., 2018). World heritage natural and cultural sites including Rock Island South Lagoon is located in Palau. Tourism is the main pillar industry of Palau, with more than $40 \%$ of GDP in Palau coming from the tourism industry (IMF p4, 2019). In the past five years especially, however, Palau has suffered from over-tourism due to the rapid development of tourism and over influx of tourists. However, because of complex political factors and weak market controllability, Palau's tourism forecast is not optimistic.

Between 2015-2018, compared with other popular tourism countries in the Pacific, Palau's tourism development even showed negative growth, with its percent growth at $-35.15 \%$. The source of tourists also changed dramatically, and the number of mainland Chinese tourists declined sharply. In 2015, Palau experienced its peak of the number of tourists, 163,905 , and

since then the number has been steadily decreasing (PVA statistics, 2019). In The unexpectedly high number of tourists(IMF p4, 2019) meant that both the residents and the environment of Palau were unprepared and not able to cater to the demands of the tourists, which lead to the tourism carrying capacity of this small island being exceeded. According to the definition by the World Tourism Organization, tourism carrying capacity is "the maximum number of people that may visit a tourist destination at the same time, without causing destruction of the physical, economic, socio-cultural environment and an unacceptable decrease in the quality of visitors' satisfaction" (UNWTO, 1981).

In short, the situation of over-tourism has effected Palau since its peak of 2015, along with environmental degradation, social impacts, biodiversity threats, inflation, and the decreasing quality of tourism experiences. As a result, the Palau government reduced the number of chartered flights in 2015 (BBC NEWS, 2017) and published "Palau Responsible Tourism Policy Framework" in December 2016, in order to improve both quality and quantity of tourism. In the policy framework, Palau positions itself as a niche market and plans to target high-end customers by promoting responsible tourism due to limited capacities and the preservation its most valuable asset, the environment (Bureau of Tourism of Palau, 2016). However, as mentioned above, the attitude of the community is one of the 
determinants of tourism development. Both local stakeholders and government are critical for obtaining support of sustainable tourism development.

\section{Analysis and Results}

\subsection{Analysis of Interviews of Three Residents}

\subsubsection{Taxi Driver}

The first interviewee works at a mid-size local hotel. His daily job is hotel security, while he works as a taxi driver part-time. He used to work as an ocean tour guide and boat operator for a tour company. This study imported the driver's interview records into NVivo software and selected the "Word Frequency Analysis" option to draw the following conclusions, as shown in Table 1.

Table 1. High Frequency Words of Taxi Driver

\begin{tabular}{lllll}
\hline Word & \multicolumn{5}{c}{ length counthted percentage (\%) Similar words } \\
\hline going & 5 & 40 & 3.50 & become, going, operate, operator, operators, run, start, started, tour, worked, working \\
like & 4 & 23 & 2.75 & like \\
tourists & 8 & 19 & 2.27 & tourist, tourists \\
pay & 3 & 23 & 2.03 & earn, earned, give, paid, pay, salary \\
come & 4 & 17 & 1.91 & become, come, comes, coming, total \\
people & 6 & 16 & 1.91 & people \\
good & 4 & 18 & 1.80 & depends, good, just, right, security \\
changed & 7 & 14 & 1.67 & change, changed, changing, transferred \\
support & 7 & 14 & 1.56 & assist, assistant, back, encouraging, friend, friends, fund, help, suffered, support \\
see & 3 & 14 & 1.48 & find, image, picture, see, visit \\
\hline
\end{tabular}

In Table 1, we can see that the main concern of this taxi driver is the "paying capacity" of tourists in Palau. This finding shows that tourism income accounts for a large part of the salary system of grassroots practitioners. By contrast, in the whole interview, the 'environment' was mentioned only couple times; it was basically negligible. This visualization of the word frequency can visually show the subjective concerns of the current respondent. It means that his primary concern is how many tourists and how much income could be brought to Palau via tourism, as shown below:

"In Palau, we like tourism. Tourism is all good. I don't believe that tourism will be harmful for the environment. I like more tourists come to Palau. I like more people come to Palau and push everything."

\subsubsection{A Government Officer from Palau Visitors Authority (PVA)}

The second respondent had worked for various government departments for 14 years. He has a strong background in banking and finance. He offered a unique perspective, expressing the beliefs and thoughts of the Palau government. 
Table 2. High Frequency Words for the Officer of PVA

\begin{tabular}{lllll}
\hline Word & \multicolumn{5}{c}{ length counthted percentage (\%) Similar words } \\
\hline people & 6 & 17 & 2.99 & people \\
number & 6 & 21 & 2.64 & bit, come, comes, coming, issue, issues, number, numbers, turned \\
work & 4 & 15 & 2.22 & brings, going, operations, turned, work, worked, working \\
impacts & 7 & 13 & 2.02 & affect, impact, impacted, impacts \\
negative & 8 & 10 & 1.76 & negative \\
now & 3 & 12 & 1.76 & direction, now \\
think & 5 & 10 & 1.76 & reasons, think \\
positive & 8 & 14 & 1.57 & advantages, attitudes, office, placing, position, positive, positively, put, set, states \\
development & 11 & 11 & 1.53 & development, getting, prepare, prepared \\
direction & 9 & 19 & 1.43 & $\begin{array}{l}\text { direction, heading, manage, management, managers, managing, organization, } \\
\text { placing, take, target, targets, way }\end{array}$ \\
\hline
\end{tabular}

In Table 2, it can be seen that this government official pays more attention to the development of the tourism industry and the overall economic volume of the industry. Compared to the other two interviewees, he emphasizes more of the positive effects of the policy of tourism development. At the development level, he takes into consideration the macro-industry situation. It can be concluded that his thinking tends to be in line with the government, as his quotation below suggests:

“We are going to host the 'Our Ocean Conference 2020' in Palau. It is a huge event that expresses why Palau is pristine paradise. The most important is conservation. Once you protect what we have and you maintain that. Conservation is a key part of tourism."

\subsubsection{A General Manager of Belau Tour Company}

The third respondent is a professional manager from Japan who has lived in Palau most of his life. He is considered a "wisdom elder" in the community with his own unique understanding of Palau's local economy. The "word frequency analysis" table obtained by importing his interview records into NVivo software is shown in Table 3. It can be seen that this business manager paid more attention to inbound tourism. And in terms of language expression, he put more emphasis on the needs of the people. His answer is clear and his attitude towards tourism development is positive, as shown in the quote below:

"So that step by step, we have to increase the guest slowly, that is the best solution... We have to respect tourism. We need a good balance; it is the best way for Palauan and the tourists... We have to protect the environment... The first one is steadily growing, step by step. The other one is diversified to different countries...We need the balance between the number of the tourists and the capacity of Palau."

Table 3. High Frequency Words for Manager

\begin{tabular}{lllll}
\hline Word & \multicolumn{5}{c}{ Length counthted percentage (\%) Similar words } \\
\hline countries & 9 & 25 & 2.19 & countries, countries', country \\
come & 4 & 31 & 2.15 & arrival, come, coming, follows, get, getting, number, total \\
need & 4 & 31 & 2.15 & ask, demand, need, needs, take, takes, want \\
people & 6 & 24 & 2.10 & people \\
like & 4 & 24 & 1.93 & care, like, similar \\
many & 4 & 21 & 1.84 & many \\
think & 5 & 22 & 1.62 & believe, mean, means, reason, reasonable, think, thinking \\
going & 5 & 25 & 1.36 & get, getting, going, live, living, move, operators, sound, survive, tour, worked \\
good & 4 & 19 & 1.34 & depends, good, just, respect, right, security, sound, well \\
flight & 6 & 15 & 1.31 & flight, flights \\
\hline
\end{tabular}


From the above analysis, it can be concluded that the word frequency of the three interviewees are different from each other. Their highest frequency words have revealed their attitudes toward tourism development. For Taxi driver, it is "going", implying job opportunity. For the GM, it is "countries", implying he thinks on the macro side and pays more attention to the impact of national policies. For the "government officer", it was "people". Unlike the first two interviewees, "people" do not have similar words in the interview process. This means that his focus is on the "people's attitude to policy." By analyzing the high-frequency word relationships in the interview process of the three interviewees, this study yields the following "word cloud" relationship cycle diagram.

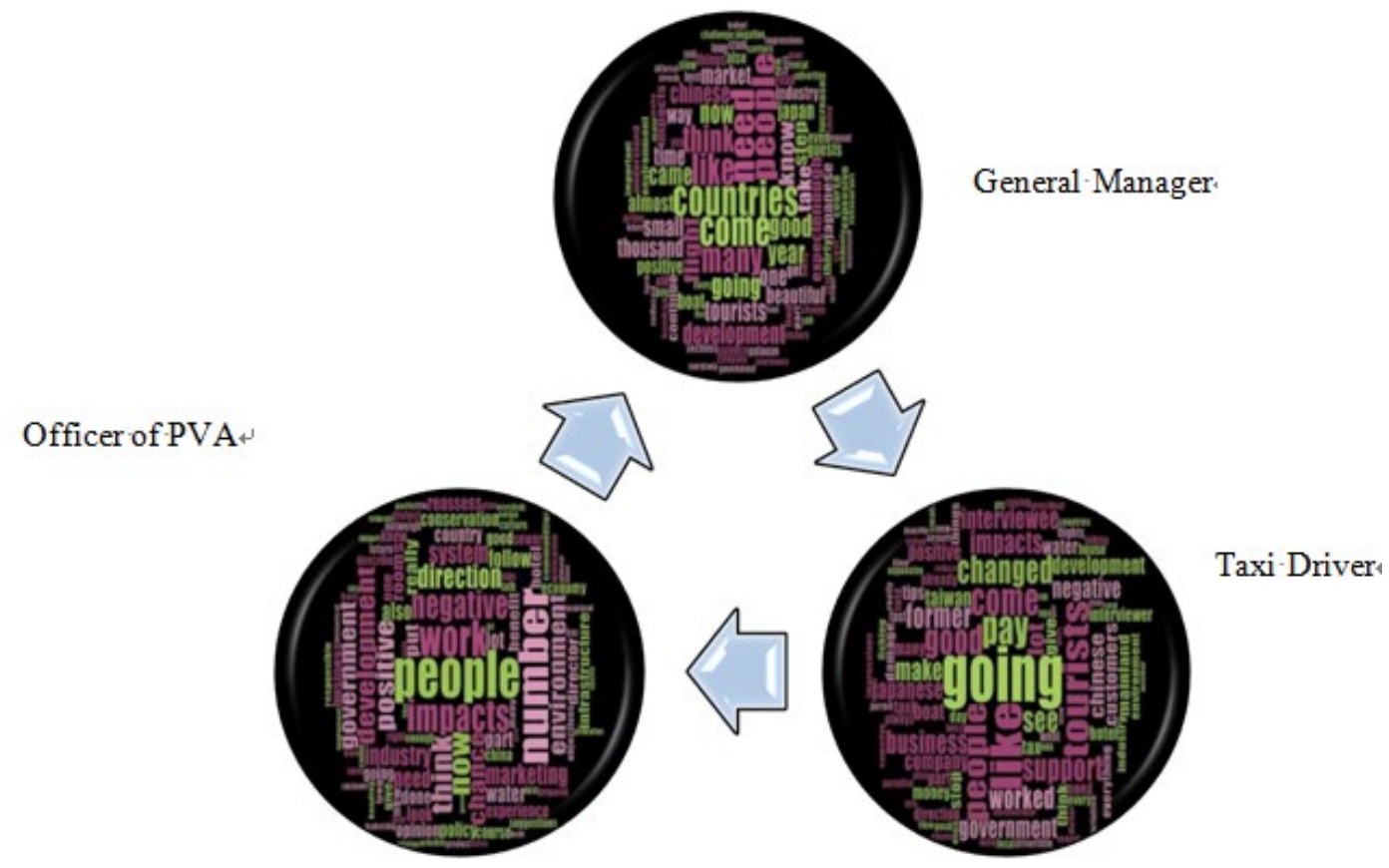

Figure 1. Interview with Social Relationship Cycle (Word Frequency Display)

In Figure 1, national policies affect the operating form of enterprises (GM high-frequency word "countries") affect the employment opportunities of the bottom people (Taxi driver high- frequency word "going"), and the attitudes of the bottom people affect government policies (officer high-frequency word "people"), which influences policy making. Policies continue to affect economic development and form a closed cycle. These three respondents represent both themselves and their social class. Each class has different expectations for society. The comprehensive analysis of these three can objectively reflect the mainstream views of social themes. After completing the analysis of the three respondents, this study subsequently conducted a re-counting of the total frequency of the interview words among the three respondents.

Based on the overall word frequency statistics above, it can be concluded that the exact word frequency is: "The inbound tourists to Palau occupy an important position in the minds both of the local people and government officials alike. These tourists create wonderful economic incomes."(Word frequency statistical reasoning) The above are the preliminary conclusions reached through interviews in this study. 
Table 4. High frequency words

\begin{tabular}{|c|c|c|c|c|}
\hline \multicolumn{2}{|l|}{ Word } & \multicolumn{3}{|c|}{ length count ted percentage $(\%)$ Similar words } \\
\hline people & 6 & 57 & 2.24 & people \\
\hline going & 5 & 83 & 2.09 & $\begin{array}{l}\text { become, get, getting, going, live, living, move, operate, operations, operator, operators, } \\
\text { run, sound, start, }\end{array}$ \\
\hline & & & & started, survive, tour, tours, travel, turned, work, worked, working \\
\hline come & 4 & 68 & 1.97 & $\begin{array}{l}\text { arrival, become, come, comes, coming, follow, follows, get, getting, number, numbers, } \\
\text { total }\end{array}$ \\
\hline like & 4 & 49 & 1.83 & care, like, potential, similar \\
\hline tourists & 8 & 35 & 1.38 & tourist, tourists \\
\hline think & 5 & 39 & 1.32 & believe, imagine, mean, means, reason, reasonable, reasons, think, thinking \\
\hline need & 4 & 46 & 1.30 & ask, demand, need, needs, take, takes, want, wanted \\
\hline country & 7 & 37 & 1.29 & area, countries, countries', country, land, national, state, states \\
\hline good & 4 & 45 & 1.29 & depends, good, just, respect, right, security, sound, well \\
\hline impacts & 7 & 32 & 1.20 & affect, impact, impacted, impacts \\
\hline
\end{tabular}

\subsection{Analysis of Secondary Data}

\subsubsection{Analysis of Government Reports}

After analyzing the primary data, the study continued to analyze the secondary data of government reports. The result is shown in Figure 2. According to the visual display of the "word cloud", the focus of the Palau local government policy is "the target market for the development of tourism [which] comes from international tourists. Tourism has an important position in the economy and [is needed] to maintain GDP growth." (The IMF (2019), Republic of Palau) In short, the government cannot suppress the development of tourism, but the government's direction will guide the transformation of low-end tourism to high-end tourism.

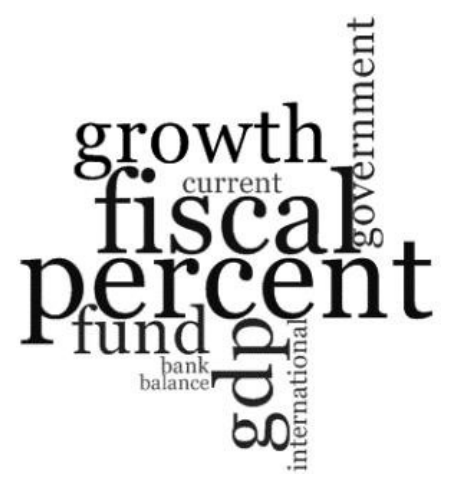

Figure 2. Government Report Word Frequency

\subsubsection{Analysis of Three Journal Articles}

The word frequency statistics on three articles about Palau tourism are shown in Table 5. It can be seen that at the present time, tourism research about Palau mainly focuses on development. Although the number of tourists has declined in recent years, Palau's tourism resources have not been fully developed yet. Upgrading the tourism industry to cater to high- end tourist experiences and items is an important direction for Palau's future. 
Table 5. High Frequency Words

\begin{tabular}{|c|c|c|c|c|}
\hline \multirow{2}{*}{$\begin{array}{l}\text { Word } \\
\text { development }\end{array}$} & \multicolumn{4}{|c|}{ length count ted percentage (\%) Similar words } \\
\hline & 11 & 271 & 1.17 & $\begin{array}{l}\text { acquires, arise, break, breaks, develop, developed, developers, developing, development, } \\
\text { developments, develops, educated, education, evolut, evolution, evolve, evolves, evolving, } \\
\text { exploitation, formulate, formulated, formulating, formulation, get, grow, growing, grows, } \\
\text { growth, } \\
\text { mature, modern, origin, originally, originating, produce, produced, producing, rise, training }\end{array}$ \\
\hline reef & 4 & 175 & 0.92 & reef, reefs, reefs' \\
\hline local & 5 & 207 & 0.87 & $\begin{array}{l}\text { local, localities, localized, locally, locals, locals', locate, located, location, locations, locus, } \\
\text { place, } \\
\text { placed, places, section, sections, set, setting }\end{array}$ \\
\hline policy & 6 & 144 & 0.76 & policies, policy \\
\hline residents & 9 & 138 & 0.72 & hall, halls, occupation, residence, resident, residents, residents', residents', rest \\
\hline study & 5 & 199 & 0.71 & $\begin{array}{l}\text { analyses, analyze, analyzed, analyzing, considered, considering, disciplines, examination, } \\
\text { examine, } \\
\text { examined, field, learning, read, reading, report, reported, reporting, studied, studies, study, } \\
\text { subject, survey, surveys, take, taking, work, working }\end{array}$ \\
\hline economic & 8 & 154 & 0.70 & $\begin{array}{l}\text { conserv, conservancy, conservation, conservatively, conserve, economic, economically, } \\
\text { economics }\end{array}$ \\
\hline impacts & 7 & 115 & 0.59 & affect, affected, affects, impact, impacts, shocks \\
\hline state & 5 & 192 & 0.57 & $\begin{array}{l}\text { commonwealth, countries, country, declared, express, formal, formally, land, landed, } \\
\text { lands, nation, } \\
\text { national, nationality, nations, posited, position, positioned, positioning, positions, positive, } \\
\text { positively, posits, province, state, stated, states, submit }\end{array}$ \\
\hline tourists & 8 & 104 & 0.55 & tourist, tourists, tourists' \\
\hline
\end{tabular}

\subsection{Analysis of Interviews, Articles and Palau Government Reports}

Along with the above research, this research integrated the results of interviews, and news articles with Palau government reports. Again, using the NVivo software, the strategy can be obtained by analyzing the word frequency (as shown in Figure 3).

According to the word frequency statistics, it can be seen that the Palau government puts great importance to the industrial status of the tourism industry and its constant development (IMF, 2019). The government's main goals are to maintain economic development and maintain social stability. Residents from a lower social class have a low sensitivity to policies but put an emphasis on the great impact of income changes. The social elite has a strong sense of social responsibility and strategic thinking. They are more supportive of the government's tourism industry upgrade plan. 


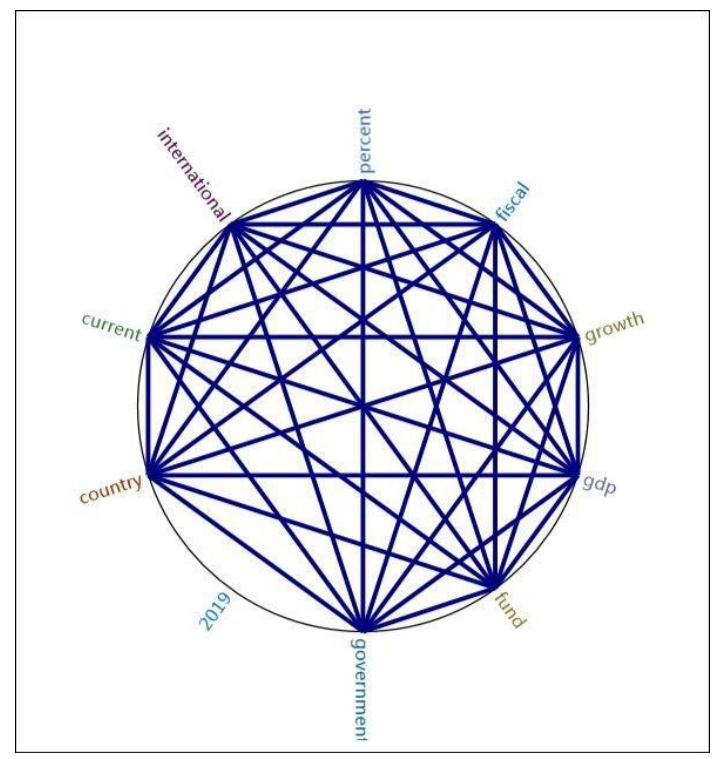

Figure 3. Comprehensive Word frequency cluster analysis Data (First 10 words)

\section{Discussion}

It is appropriate to use TALC to frame tourism development in Palau from 1995 to 2019 (refer to Figure 4). From 1995 to 2003, Palau was in the Exploration and Involvement stages. Between 2003 to 2011, it entered the Development stage, with foreign investment in resorts, tour companies and restaurants. From 2011, heading into the Consolidation stage, Palau experienced slower growth rates of tourist numbers and the total number of visitors was not just an upward trend while it approached the critical range of the element of capacity. In 2014, unexpectedly, the number of the Mainland Chinese tourist rocketed from 9,000 to 90,000 in two years. Since then, these numbers have started to decline. The capacity and resources of destination are finite. Combine this with the substantial decrease in the number of tourists in recent years and this implies that Palau is entering the stage of Stagnation and Decline.

What are the residents' attitudes towards the impact? Based upon the above results, it is obvious that opinions differ between the demographics of the interviewees, but one thing is universal: all Palauans welcome inbound tourists and the economic support they offer. This finding matches the SET in the respect that residents who depend on tourism have a positive attitude towards the contribution of tourism industry and have a tolerant attitude towards the negative impact (Faulkner \& Tideswell, 1997). It also can be explained by resident-tourist emotional solidarity theory; the residents display a welcoming nature (Woosnam \& Norman, 2010) and appreciate the contribution tourists make to the community (Wang \& Pfister, 2008). On the other hand, government officials and academics also show the same interest in tourism development. This supports Untong et al. (2010)'s statement that the economic benefits have the most direct relationship with the attitude of local residents towards tourism. As a whole, Palau has the strong emotional bond with tourists.

Nevertheless, Palau also has strong sense of the need for sustainable tourism. This gives the optimal solution regarding the trade-off between tourism development and environmental conservation. According to the above results, people may not all be interested in conservation scheme. However, the government and elites definitely intend to sustain tourism resources and the environment of Palau. A win-win strategy thus comes up as SET indicates that maintaining economic development while reducing environmental damage and protecting natural resources, addresses the mutual benefits of both the host community and tourists. This win-win plan as analyzed by NVivo is defined as "Development and Growth". In action, it advocates tourism development in paralleling the marketing strategy to upgrade Palau tourism to the high-end market and to reduce low-end tourism items. 


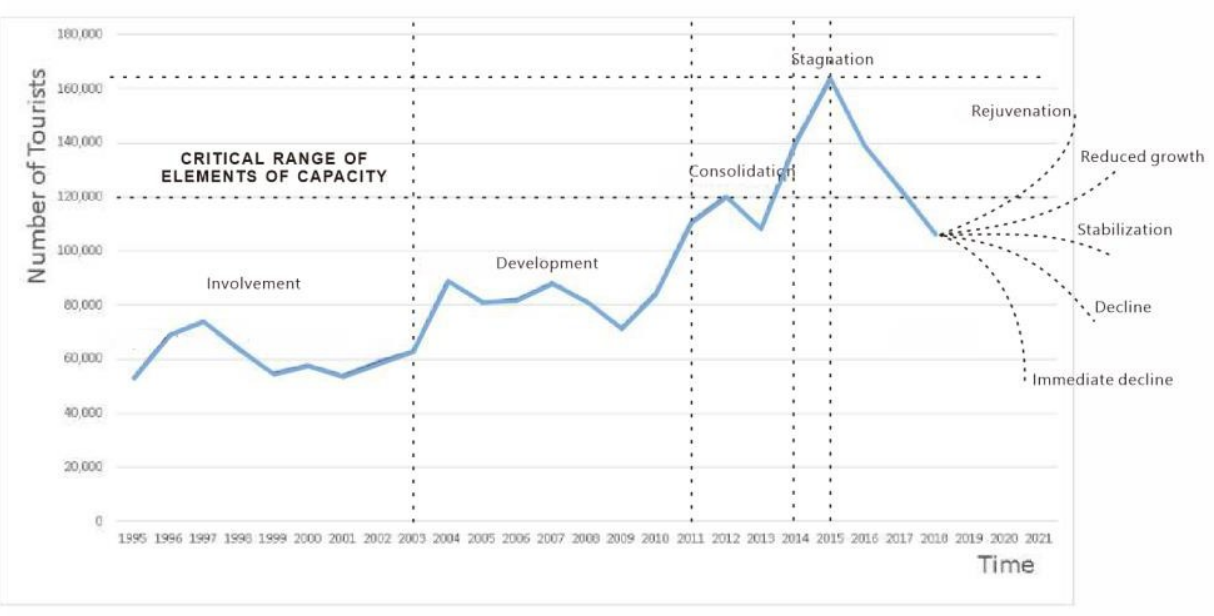

Figure 4. Evolution of Palau tourism by Butler's TALC model

\section{Conclusion}

This research aims to examine the Palau community's attitudes towards the stagnation of tourism development using both primary and secondary research data in order to propose an appropriate plan. Via the NVivo analysis, a meaningful insight has been found. At the turning point of stagnation and recovery, the community, including residents, academics, and government, is in favor of the development of tourism and the encouragement of more inbound tourists but only in conjunction with environmental protection policies. To achieve this goal, the marketing strategy is focused on upgrading Palau tourism to the high-end market. This finding implicates a win-win solution for the destination in confronting the trade-off between tourism development and environmental conservation. The above suggestions could bridge the gap in the literature surrounding this topic and produce a useful tourism planning strategy with the purpose of maintaining keeping Palau as a thriving yet sustainable ecotourism destination.

Nevertheless, this study has several limitations that need to be improved in future studies. First of all, this study focused only Palau; different countries or regions should exercise caution when interpreting these results. Secondly, this study conducted only three interviews, a bigger sample will be necessary for future research. Thirdly, this study used a qualitative analysis method, the quantitative methods should be used as a supplement to further explore the attitudes of the host community towards tourism.

\section{References}

BBC News. (2017). Palau Leader Proposes 'Luxury Only' Tourism. Retrieved from https://www.bbc.com/news/blogs-news-from-elsewhere-38570837 on 2019-12-08

Butler, R. (1980). The Concept of a Tourism Area Cycle of Evolution: Implications for the Management of Resources. Canadian Geographer, 24(1), 5-12. https://doi.org/10.1111/j.1541-0064.1980.tb00970.x

Butler, R. (2000). The Resort Cycle Two Decades On. In B. Faulkner, E. Laws \& G, Morcado (Editors), Reflections on Experience, 284-298. London: Cassell.

del Mar Delgado-Serrano, M., Mistry, J., Matzdorf, B., \& Leclerc, G. (2017). Community-based management of environmental challenges in Latin America and the Caribbean. Ecology and Society, 22(1). https://doi.org/10.5751/ES-08924-220104

Dredge, D., Jenkins, J., \& Whitford, M. (2011). Tourism Planning and Policy: Historical Development and Contemporary Challenges. In D. Dredge \& J. Jenkins (Eds.), Stories of practice: Tourism policy and planning (pp. 13-36). Farnham: Ashgate.

Durkheim, E. ([1912] 1995). The Elementary Forms of the Religious Life. New York, NY: Free Press.

Faulkner, B., \& Tideswell, C. (1997). A framework for monitoring community impacts of tourism. Journal of sustainable tourism, 5(1), 3-28. https://doi.org/10.1080/09669589708667273 
Homsud, N., \& Promsaard, S. (2015, April). The effects of residents' image and perceived tourism impact to residence satisfaction and support: A case study of hua-hin prachubkirikhan. In The 2015 WEI International Academic Conference Proceedings (pp. 190-199).

Johnston, M. P. (2014). Secondary Data Analysis: A Method of Which the Time has Come. Qualitative and Quantitative Methods in Libraries, QQML, 3, 619 -626.

Lincoln, S. Y., \& Guba, G. E. (1985). Naturalistic Inquiry. Newbury Park, CA: Sage.

Maslow, A. H. (1943). A theory of human motivation. Psychological review, 50(4), 370. https://doi.org/10.1037/h0054346

McCool, S. F., \& Moisey, R. N. (2009). Tourism, Recreation, and Sustainability: Linking Culture and Environment. Cromwell Press. UK.. https://doi.org/10.1079/9781845934705.0000

McKercher, B. (2006). Are psychographics predictors of destination life cycles?. Journal of Travel \& Tourism Marketing, 19(1), 49-55. https://doi.org/10.1300/J073v19n01_05

Miyakuni, K., Fujita, Y., Koshiba, S., \& Rengiil, G. (2018). Residents' attitudes toward tourism in an island destination, focusing on Ecocentric attitudes: The case of the Republic of Palau. Palau International Coral Reef Center.

Nunkoo, R., \& Ramkissoon, H. (2011). Developing a community support model for tourism. Annals of Tourism Research, 38(3), 964-988. https://doi.org/10.1016/j.annals.2011.01.017

Schofield, P. (2011). City resident attitudes to proposed tourism development and its impacts on the community. International journal of tourism research, 13(3), 218-233. https://doi.org/10.1002/jtr.814

Sharma, N., \& Sarmah, B. (2019). Consumer engagement in village eco-tourism: A case of the cleanest village in Asia-Mawlynnong. Journal of Global Scholars of Marketing Science, 29(2), 248-265. https://doi.org/10.1080/21639159.2019.1577692

Silverman, D., \& Marvasti, A. (2008). Doing Qualitative Research. Los Angeles: SAGE Publications.

Stumpf, T. S., \& Swanger, N. (2015). Tourism involvement-conformance theory: A grounded theory concerning the latent consequences of sustainable tourism policy shifts. Journal of Sustainable Tourism, 23(4), 618-637. https://doi.org/10.1080/09669582.2014.959967

The Bureau of Tourism. (2016). Palau Responsible Tourism Policy Framework 2017-2021. The IMF (2019), Republic of Palau. IMF Country Report, No. 19/43. https://doi.org/10.5089/9781484397916.002

Untong, A., Kaosa-Ard, M., Ramos, V., Sangkakorn, K., \& Rey-Maquieira, J. (2010, July). Factors influencing local resident support for tourism development: A structural equation model. In The APTA Conference, Macau, China (pp. 1-21).

World Tourism Organization. (1981). Saturation of tourist destinations: Report of the Secretary General.

Wabnitz, C. C., Cisneros-Montemayor, A. M., Hanich, Q., \& Ota, Y. (2018). Ecotourism, climate change and reef fish consumption in Palau: Benefits, trade-offs and adaptation strategies. Marine Policy, 88, 323-332. https://doi.org/10.1016/j.marpol.2017.07.022

Wang, Y., \& Pfister, R. E. (2008). Residents' attitudes toward tourism and perceived personal benefits in a rural community. Journal of Travel Research, 47(1), 84-93. https://doi.org/10.1177/0047287507312402

Woosnam, K. M., \& Norman, W. C. (2010). Measuring residents' emotional solidarity with tourists: Scale development of Durkheim's theoretical constructs. Journal of Travel Research, 49(3), 365-380. https://doi.org/10.1177/0047287509346858

Yoon, Y., Gursoy, D., \& Chen, J. S. (2001). Validating a tourism development theory with structural equation modeling. Tourism management, 22(4), 363-372. https://doi.org/10.1016/S0261-5177(00)00062-5 


\section{Appendixes}

\section{Appendix 1: NVivo Automatic Coding}

In this study, NVivo software was used to auto-encode the research interview questionnaire. NVivo software's automatic encoding function can check the emotional direction of files. Through the automatic coding test, the author can confirm that the interview questionnaire has no obvious emotional tendency. This means that the interview questionnaire of this study is objective and there is no emotional guidance. It can enhance the reliability and validity of this study.

Automatic coding can expose any emotional tendency of the interview file, so that it can analyze the subjective opinions of the interviewees on the content of the interview. This study performed an automatic coding check on the interview records of the three interviewees. The results show that:

a) the neutral attitude of the three interviewees in the interviews is the absolute advantage;

b) the proportion of vague attitudes between positive and negative attitudes of taxi driver respondents is very high;

c) the attitude of PAV Officer Interviewees, positive emotions account for a large proportion;

d) GM has obvious positive and negative attitudes in the interview. The proportion of mixed attitudes in the middle is very small, which is exactly the opposite of the attitude of taxi drivers.

Positive and negative attitudes mean a clear understanding of the questionnaire. From the statistics, it can be concluded that business managers and government officials have a clear attitude towards the tourism economy. Although middle and lower-level workers have earned economic benefits, the understanding of the tourism economy is still relatively vague. Figure

A.1 shows the proportion of emotions among the three respondents.

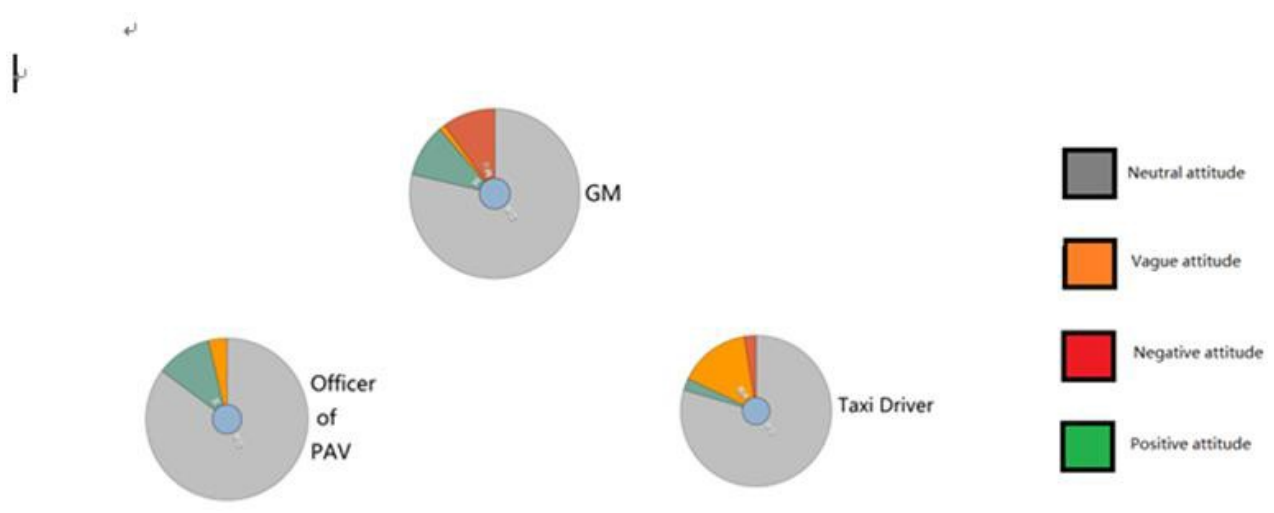

Figure A.1. Respondents' Emotional Tendencies for Questionnaire Interviews

\section{Appendix II: Semi-Structured Questionnaire}

Part I: Interviewees Profile (General Information)

1. May I know your position in your organization? (Could you describe your main responsibilities?)

2. How many years have you worked in the tourism industry or other relevant industries?

3. Would you mind telling us your age? 
Part II: Perceptions to impacts of tourism development

1. Could you describe your impressions of Palau tourism?

2. What's your opinion about tourism's positive impacts to Palau? What do you think of them?

3. What are the negative impacts of tourism in Palau? What do you think of them?

4. Do you think the positive benefits of tourism outweigh negative impacts or the negative impacts of tourism outweigh positive impacts?

5. What is your biggest concern about the tourism development of Palau?

6. Will you support or oppose tourism development in Palau? Why?

\section{Part III: Suggestions}

1. What do you think are the main challenges of Palau tourism development?

2. What direction do you expect Palau's tourism development in the future?

3. What suggestions would you give for tourism development in Palau? 